http://jmscr.igmpublication.org/home/ ISSN (e)-2347-176x ISSN (p) 2455-0450 crossref DOI: https://dx.doi.org/10.18535/jmscr/v8i2.72

\title{
Practice of Universal Precaution among Health Care Providers in a Tertiary Care Hospital in Tripura: A Cross- Sectional Study
}

Authors

\section{Dr Rituparna Das ${ }^{1}$, Dr Arpita Debnath ${ }^{2}$, Dr Paramita Barman ${ }^{2}$}

${ }^{1}$ Assistant Professor, Dept. of Community Medicine Agartala Government Medical College, Tripura ${ }^{2}$ Post Graduate Resident, Dept. of Community Medicine, Agartala Government Medical College, Tripura *Corresponding Author

\section{Dr Rituparna Das}

Assistant Professor, Dept. of Community Medicine, Agartala Govt. Medical College, Agartala, Tripura (W). Pin-799006, India

Abstract
Health care providers are at risk of blood borne infections as an occupational hazard. This can be
prevented by adequate practice of universal precaution.
Objective: 1 . To estimate the practice of universal precaution among health care providers 2. To assess
the barriers of universal precaution practice among health care providers. 3.To study the factors
associated with practice of universal precaution.
Material and Method: This was a hospital based cross- sectional study conducted among 180 health
care providers during March, 2018 at Agartala Government Medical College and G.B.P. Hospital,
Agartala. Stratified random sampling procedure was used to select the participants and a scoring system
was used to assess the practice of universal precaution.
Results: The present study revealed that $13.4 \%$ participants were having good practice of Universal
precaution, $67 \%$ participants were having average practice, $19.6 \%$ having poor practice regarding
universal precaution. Majority of the participants could not comply with Universal Precautions due to
increased work load (78.4\%), followed by Emergency cases (65.6\%).Occupation and work experience
were found as significant determinants of universal precaution practice (p value- <0.05).
Conclusion: The Overall Practice of universal precaution was not satisfactory. Training programmesfor
the health-care providers to update the existing knowledge, better work place managementcan help in
having a positive attitude and compliance to universal precaution.
Keywords: Universal precaution, Practice, Health-care providers.

\section{Introduction}

Healthcare providers are potentially exposed to blood and body fluids and are at risk of blood borne infections like HIV, HBV, HCV, etc. as an occupational hazard. The World Health Organization (WHO) estimates that about $2.5 \%$ of HIV cases among health care providers and $40 \%$ of hepatitis B and C cases among HCPs worldwide are the result of this exposures. ${ }^{1}$

According to CDC guidelines universal precaution are set of actions which are required to prevent infections from blood borne or body fluid borne infection. The major practices recommended in universal precaution are hand washing, use of 
protective barriers to prevent direct contact, safe handling and disposal of sharps; safe decontamination of instruments etc. Main aim of universal precaution is to protect health workers and patients from infection. ${ }^{2}$ Despite detailed guidelines, the practice of universal precautions among Health care providers in developing countries is poor and their occupational safety remains a neglected issue. ${ }^{3,4}$ Again there is paucity of information regarding the practice of universal precaution among various health care providers in the North Eastern part of India. Hence, the present study was conducted to estimate the practice of universal precaution among health care providers and to find out the barriers of universal precaution practice among them. The study also aims to assess the factors affecting the practice of universal precaution.

\section{Methodology}

It was a hospital based Cross-sectional study conducted in Agartala Government Medical College and G.B.P Hospital, Agartala during March, 2018 among health care providers. The study included Doctors, Interns, Nurses, who were posted in clinical departments and technicians posted in Central laboratory, Department of Microbiology, Pathology, Biochemistry; during the study periodas health care providers. The study excluded those who did not give consent to participate in the study and also excluded Senior Faculty members considering that they would be infrequently involved in handling needles in their daily patient care. The sample size was calculated to be 185 considering a prevalence of practice of UP to be $62 \%$, at $5 \%$ level of significance and with an absolute precision of 7 . However, since stratified random sampling technique was used the sample size was multiplied by 0.8 (design effect) and considering a $20 \%$ Non-response rate, the sample size was rounded to180 Health Care Providers.

Stratified sampling procedure was adopted and the health care providers were divided into strata of Resident Doctors, Interns, Nurses, and lab technicians. Considering probability proportionate to size technique 28 Resident Doctors, 28 Interns, 112 Nurses, and 12 lab technicians were randomly selected from each strata. Information was collected by using a pre-tested, structured interview schedule after taking informed consent from the selected participants along with real time supervision of the practice of universal precaution of health care practitioners.

Data was analysed using SPSS version 25.0 and statistical analysis was done using Chi-square tests and a $\mathrm{p}$ value of $<0.05$ was deemed as statistically significant. The Practice of universal precaution was assessed on a 8 point scale. The median score was 6 and practice of the participants was categorized as, Good practice: A score $>75^{\text {th }}$ percentile (score of 8); Average practice: A score $25^{\text {th }}-75^{\text {th }}$ percentile (score 5-7); Poor practice: A score $<25^{\text {th }}$ percentile (score $<5$ ). Due to lack of availability of adequate gowns and goggles for day to day use, even use of spectacles and apron with proper body cover was considered operationally as use of universal precaution. The study was conducted as a part of study titled "Occupational Exposure to Needle Stick Injuries and practice of Universal Precautions among Health Care Providers in a Tertiary Care Hospital in Agartala: A Cross- Sectional Study" and was approved byInstitutional Ethics Committee of Agartala Government Medical College.

\section{Results}

The present study was conducted among 180 health care providers working in a tertiary care hospital. The study revealed that majority of the respondents were between 20-30years age group $(61.1 \%), 63.3 \%$ were female, and majority of the respondents $(33.3 \%)$ were having job experience of 1-5 years. (Table 1)

Table 2 shows practice of various universal precaution measures according to occupation. Majority of the HCP were practicing proper sharp disposal techniques $(96.1 \%)$ followed by wound covering $(91.7 \%)$ during patient care. Hand washing was regularly practiced by only $62.8 \%$ of 
the participants, however, on observation majority performed social hand washing and were not following 6 steps of hand washing. Again, none used goggles or plastic gown due to lack of availability for day to day work. However, $16.1 \%$ respondents were using spectacles and $90.6 \%$ were using aprons regularly which was giving them certain protection. Across various occupations, the practice of different measures of universal precaution was high among the nurses compared to doctors, interns and lab technicians. Regarding the overall practice of universal precaution, the study revealed that $13.4 \%$ of Health Care Providers were having good practice, $67 \%$ were having average practice and $19.6 \%$ were having poor practice of universal precaution respectively. (Fig 1)

Table 3 shows that poor practice of universal precaution was high among the technicians (50\%) and occupation of the participants was significantly affecting the practice of universal precaution ( $\mathrm{P}$ value 0.002).Again, the study revealed that the practice of universal precaution was high within 5 years of job whereas the practice reduced from 5 to 10 years and onwards and duration of service was significantly associated with universal precaution ( $p$ value$0.004)$

Fig 2 shows the reasons given by respondents for not being able to comply with universal precautions. Majority of the participants cited that due to huge workload $(78.4 \%)$ they could not comply with the practice of Universal Precautions. Beside $65.6 \%$ respondents cited that while managing emergency cases they become unable to comply with universal precaution.

Table 1: Sociodemographic Profile of health care providers

\begin{tabular}{|l|c|c|}
\hline Variable & Frequency & Percentage \\
\hline Age: & & \\
20-30years & 110 & $61.1 \%$ \\
31-40 years & 38 & $21.1 \%$ \\
41-50 years & 18 & $10 \%$ \\
51-60 years & 14 & $7.8 \%$ \\
\hline Sex: & 66 & $36.7 \%$ \\
Male & 114 & $63.3 \%$ \\
female & & \\
\hline Occupation: & 28 & $15.6 \%$ \\
Resident doctors & 28 & $15.6 \%$ \\
Intern doctors & 112 & $62.2 \%$ \\
Nurses & 12 & $6.6 \%$ \\
Lab technician & \multicolumn{2}{|l|}{} \\
\hline Years of Job experience & 52 & $28.3 \%$ \\
\hline <1 year & 60 & $33.3 \%$ \\
\hline >1year-5years & 28 & $15.60 \%$ \\
\hline 5-10 years & 40 & $22.20 \%$ \\
\hline >10 years &
\end{tabular}

Table 2: Practice of various universal precautions measures according to occupation

\begin{tabular}{|l|c|c|c|c|c|}
\hline Types Of Practice & $\begin{array}{c}\text { Resident } \\
\text { Doctors }\end{array}$ & Interns & Nurse & Technicians & Total \\
\hline Hand washing & $21(18.6 \%)$ & $18(15.9 \%)$ & $67(59.3 \%)$ & $7(6.2 \%)$ & $113(62.8 \%)$ \\
\hline Wound covering & $22(18.7 \%)$ & $28(20.9 \%)$ & $106(54.5 \%)$ & $12(6 \%)$ & $165(91.7 \%)$ \\
\hline Gloves wearing & $24(18.9 \%)$ & $23(18.1 \%)$ & $77(60.6 \%)$ & $3(2.4 \%)$ & $159(83.3 \%)$ \\
\hline Gloves changing & $27(15.6 \%)$ & $28(16.2 \%)$ & $107(61.8 \%)$ & $11(6.4 \%)$ & $134(74.4 \%)$ \\
\hline Face mask & $26(16.3 \%)$ & $27(16.9 \%)$ & $96(60 \%)$ & $11(6.9 \%)$ & $126(70 \%)$ \\
\hline Goggles/ spectacles & $25(18.7 \%)$ & $28(20.9 \%)$ & $73(54.5 \%)$ & $8(6.0 \%)$ & $29(16.1 \%)$ \\
\hline Gown/ apron & $11(37.9 \%)$ & $1(3.4 \%)$ & $15(51.7 \%)$ & $2(6.9 \%)$ & $163(90.6 \%)$ \\
\hline Sharp disposal & $27(16.3 \%)$ & $26(15.7 \%)$ & $104(62.7 \%)$ & $9(5.4 \%)$ & $173(96.1 \%)$ \\
\hline
\end{tabular}




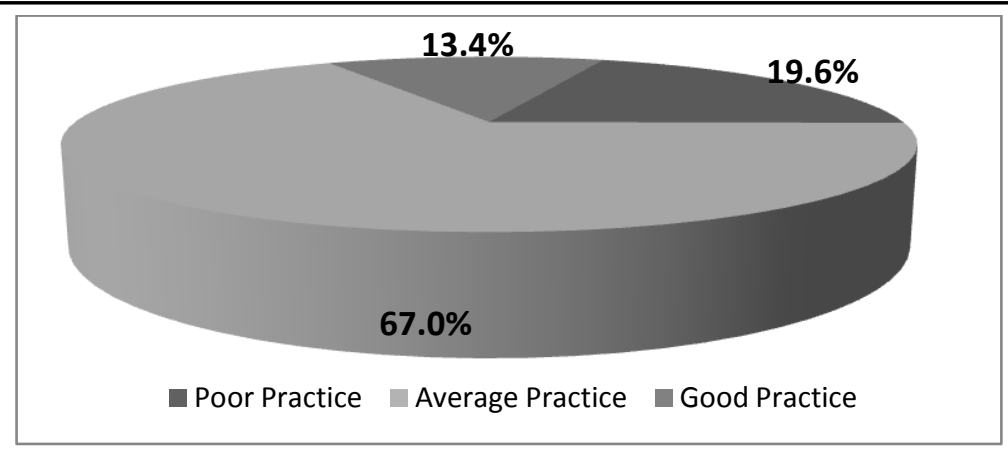

Fig1: Pie chart showing practice of universal precaution

Table 3: Factors Affecting Universal Precaution Practice

\begin{tabular}{|c|c|c|c|c|}
\hline Criteria of participants & Category & Poor practice & $\begin{array}{l}\text { Average practice / } \\
\text { Good practice }\end{array}$ & P value \\
\hline \multirow[t]{2}{*}{ Sex } & Male & $11(16.7 \%)$ & $55(83.3 \%)$ & \multirow[t]{2}{*}{0.559} \\
\hline & Female & $24(21.2 \%)$ & $89(78.8 \%)$ & \\
\hline \multirow[t]{4}{*}{ Age group (in years) } & $20-30$ & $17(15.6 \%)$ & $92(84.4 \%)$ & \multirow[t]{4}{*}{293} \\
\hline & $31-40$ & $11(28.9 \%)$ & $27(71.1 \%)$ & \\
\hline & $41-50$ & $4(22.2 \%)$ & $14(77.8 \%)$ & \\
\hline & $51-60$ & $3(21.4 \%)$ & $11(78.6 \%)$ & \\
\hline \multirow[t]{4}{*}{ Occupation } & Resident Doctors & $1(3.6 \%)$ & $27(96.4 \%)$ & \multirow[t]{4}{*}{0.002} \\
\hline & Interns & $2(7.1 \%)$ & $26(92.9 \%)$ & \\
\hline & Nurses & $26(23.4 \%)$ & $85(76.6 \%)$ & \\
\hline & Technicians & $6(50 \%)$ & $6(50 \%)$ & \\
\hline \multirow[t]{4}{*}{ Job Experience Group } & $\leq 1$ year & $7(13.46 \%)$ & $45(86.57 \%)$ & \multirow[t]{4}{*}{0.004} \\
\hline & 1-5years & $6(10 \%)$ & $54(90 \%)$ & \\
\hline & $5-10$ years & $10(35.7 \%)$ & $18(64.3 \%)$ & \\
\hline & $>10$ years & $13(32.50 \%)$ & $27(67.50 \%)$ & \\
\hline \multirow{2}{*}{$\begin{array}{l}\text { Training on Universal } \\
\text { Precautions }\end{array}$} & Yes & $11(25 \%)$ & $33(75 \%)$ & \multirow[t]{2}{*}{.502} \\
\hline & No & $24(17.9 \%)$ & $110(82.1 \%)$ & \\
\hline \multirow{2}{*}{$\begin{array}{l}\text { Vaccinated against Hep } \\
\text { B }\end{array}$} & Yes & $32(18.6 \%)$ & $140(81.4 \%)$ & \multirow[t]{2}{*}{.074} \\
\hline & No & $2(33.3 \%)$ & $4(66.7 \%)$ & \\
\hline
\end{tabular}

\section{Reasons for non compliance with Universal Precautions}

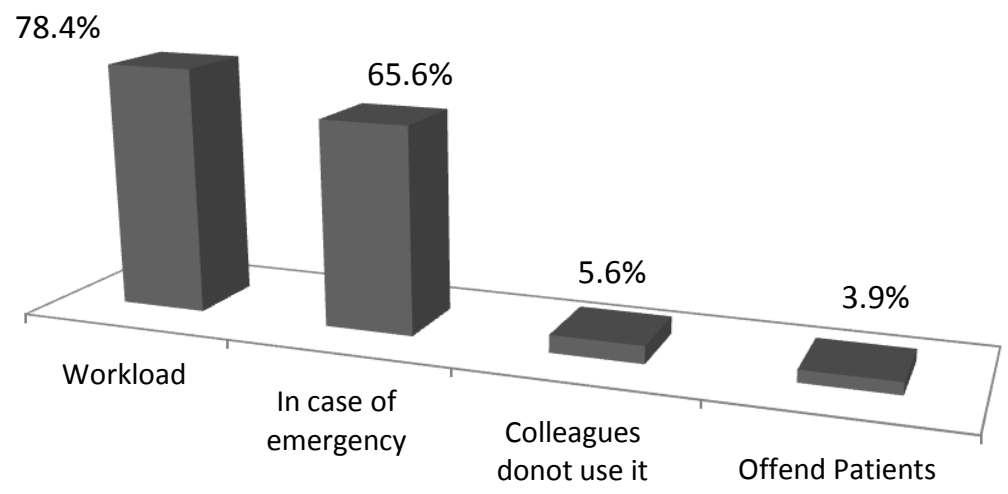

Fig 2: Reasons for non-compliance to the Universal precaution practice.

\section{Discussion}

The present study revealed that majority of the participants had average practice of universal precaution. Nurses showed better compliance to
Universal Precaution in comparison to the resident doctors, interns and lab technicians. The sharp disposal practice across all the groups were good but handwashing practice was poor. However, a 
study conducted by Singh $\mathrm{S}$ et al. in Jhanshi showed that nurses were having low level of compliance to hand washing $(64 \%)$ in comparison to doctors $(68 \%)$ and gown and mask use were low by the nurses in that study ${ }^{5}$. Another study carried out by Choudhury $\mathrm{S}$ et al. in Manipur stated that very few nurses wore mask and goggles ${ }^{6}$.The results are contradictory to our study result. This may be due the fact that using spectacles was also considered as equivalent to goggles as per operational definition though the mask usage was high. In the present study only $16.3 \%$ doctors were wearing aprons and none use plastic gowns which is much less than the study of Mukherjee et al and Jawaid $M$ et al where $56.2 \%$ and $45 \%$ of the doctors wore plastic aprons. ${ }^{7,8}$ In the present study gloves practice was $83.3 \%$ as compared to $34.2 \%$ found in a study by Choudhury s et al. ${ }^{6}$

The present study revealed that occupation and years of service was significantly associated with the practice of universal precaution. Similar findings were obtained in two different studies in Nigeria conducted by Tobin E A et $\mathrm{al}^{9}$ and Obi $\mathrm{IE}^{10}$ et al where occupation was found to be significantly associated with compliance to universal precaution. In the present study $93.3 \%$ HCPs had training on universal precaution but they are having poor or average practice which is much similar to a study carried out by Solanky P et $\mathrm{al}^{2}$ where most of the nurses were trained but only half of them were having adequate practice.

Regarding the reason for non-compliance, majority of the respondents cited that while handling emergency situation $(65.6 \%)$ and when there is increased workload $(78.4 \%)$ they could not comply with the universal precautions. Similar findings were obtained in the study conducted by Singh S. et $\mathrm{al}^{5}$ where, 'too busy to use personal protective equipments was the reason cited by majority respondents. However, the study finding was different compared to the study conducted by Choudhury $S$ et al. where lack of personal protective equipments was the major cited reason. ${ }^{6}$

\section{Conclusion}

The present study revealed that the overall practice of universal precaution was not satisfactory among the health care providers. The compliance to universal precaution was significantly affected by occupation and years of experience. Hence, frequent in-service training programmes for the health-care providers is needed to update the existing knowledge. Again, patient load management can help in having a positive attitude and compliance to universal precaution.

\section{References}

1. World Health Organization. The word health report 2002: reducing rsks, promoting health life. World Health Organization, Geneva.

2. Solanky P, Baria H, Nerulkar A, Chavda N. Knowledge and practice of universal precautions among nursing staff at a tertiary care hospital in South Gujarat, India. Int J Community Med Public Health 2016;3:2373-6

3. Kermode M, Jolley D, Langkham B, Thomas MS, Holmes W, Gifford SM. Compliance with Universal Precautions among health care workers in rural north India. Am J Infect Control 2005;33:27-33.

4. Wu S, Li L, Wu Z, Cao H, Lin C, Yan Z, et al. Universal precautions in the era of HIV/AIDS: Perception of health service providers in Yunnan, China. AIDS Behav 2008;12:806-14

5. Swati Singh, A. K Malhotra, Santosh K. Verma, Rashmi Yadav, Shubhanshu Gupta A Study on Prevalence of Practice of Universal Precautions Among Health Care Workers in Medical College, Jhansi (U.P) International Journal of Interdisciplinary and Multidisciplinary Studies (IJIMS), 2015, Vol 2,No.9,121-124. Available online at http://www.ijims.com ISSN: $2348-0343$ 
6. Chaudhuri S, Baidya OP, Singh TG.

Universal precaution: practice among doctors in a tertiary care hospital in Manipur. Int J Res Med Sci 2016;4:606-9.

7. Mukherjee S, Bhattacharyya A, Sharma Sarkar B, Goswami DN, Ghosh S, Samanta A. Knowledge and practice of standard precautions and awareness regarding post-exposure prophylaxis for HIV amonginterns of a medical college in West Bengal, India. Oman Med J. 2013;28(2):141-5.

8. Jawaid $M$, Iqbal $M$, Shahbaz $S$. Compliance with standard precautions: A long way ahead. Iranian J Publ Health. 2009;38(1):85-8.

9. Tobin EA, Asogun DA, Odia I, Ehidiamhen G. Knowledge and practice of infection control among health workers in a tertiary hospital in Edo state, Nigeria. Direct Research Journal of Health and Pharmacology (DRJHP). November 2013; 1 (2): 20-27.

10. Obi IE, Agunwa CC, Omotowo BI, Azuike EC, Ndu AC, Umeobieri AK. The Practice of Universal Precautions among Health Workers in South East Nigeria: What Factors Matter. Int. J. Med. Health. Dev. 2017; 22(1): 45-53. 